\title{
Concepts of objects and substances in language
}

\author{
Lance J. Rips ${ }^{1}$ - Susan J. Hespos ${ }^{1}$
}

Published online: 13 June 2019

(C) The Psychonomic Society, Inc. 2019

\begin{abstract}
People distinguish objects from the substances that constitute them. Many languages also distinguish count nouns and mass nouns. What is the relation between these two distinctions? The connection between them is complicated by the facts that (a) some mass nouns (e.g., toast) seem to name countable objects; (b) some count and mass nouns (e.g., pots and pottery) seem to name the same objects; (c) nouns for seemingly the same things can be count in one language (English: dishes) but mass in another (French: la vaisselle); (d) count nouns can be used to name substances (There is carrot in the soup) and mass nouns to name portions (She drank three whiskeys); and (e) some languages (e.g., Mandarin) appear to have no count nouns, whereas others (e.g., Yudja) appear to have no mass nouns. All these cases counter a simple object-to-count-noun and substance-to-massnoun relation, but they provide opportunities to see whether the grammatical distinction affects the referential one. We examine evidence from such cases and find continuity through development: Infants appear to have the conceptual OBJECT/ SUBSTANCE distinction very early on. Although this distinction may change with development, the acquisition of count/ mass syntax does not appear to be an effective factor for change.
\end{abstract}

Keywords Concepts $\cdot$ Mass and count nouns $\cdot$ Substance concepts $\cdot$ Object concepts

We can safely assume that all languages have ways of talking about both substances and objects. A language that was unable to refer to common substances like water or to common objects like people would be too limited to be of much use to its speakers. Some, and perhaps most, languages also have a grammatical distinction that corresponds loosely to this semantic one. In number-marking languages, such as English, German, Italian, and Russian, the grammatical distinction appears in the way nouns combine with plural markers, determiners, and quantifiers. Mass nouns, such as mud and gold, cannot take plural forms (*muds or *golds) except in special contexts. Similarly, they cannot be used with determiners like $a(* a$ mud or *a gold) or numeric quantifiers (*five mud(s) or *ninety-nine gold(s)). The quantifiers much and little can appear with mass nouns (much mud or little gold), but each or every cannot quantify mass nouns (*each mud or *every gold). Count nouns, such as cat or toaster, have the opposite characteristics: They take plurals (cats, toasters), determiners

Lance J. Rips

rips@ northwestern.edu

1 Psychology Department, Northwestern University, 2029 Sheridan Road, Evanston, IL 60208, USA like $a$ ( $a$ cat, a toaster), numeric quantifiers (five cats, ninetynine toasters), and each and every (every cat, each toaster) but not much or little (*much cat, *little toaster). Some nouns, such as cake, lamb, stone, rock, rope, and hair, have both count and mass forms.

Not all languages distinguish substances and objects in this way. Nouns in classifier languages (including many East Asian languages, such as Japanese, Korean, and Mandarin, and many Central and South American languages, such as Arawak and Nahuatl; see Aikhenvald, 2000) do not mark singular and plural, and they prohibit nouns of all sorts from combining directly with numeric quantifiers. Instead, a classifier expression has to precede the noun in quantifier phrases; for example, these languages express three cats in the form three + classifier + cat. Still, one can maintain that classifier languages have a grammatical encoding of substances and objects that is part of the classifier system rather than the number-marking system (Chierchia, 2010; Krifka, 1989). For example, some classifiers (count or individual classifiers) seem restricted to whole objects, whereas others are not (e.g., Chien, Lust, \& Chiang, 2003; Gao \& Malt, 2009).

Some additional languages (e.g., Dagaare, Maltese, Welsh) possess not only mass and count nouns but also a third type of noun with characteristics opposite those of ordinary singular 
and plural count nouns. In English and other number marking languages, singular nouns (e.g., cat, table) have a simple (unmarked) structure and refer to individual items, whereas plural forms (cats, tables) have a more complex (marked) structure and refer to pluralities. Welsh and similar languages have ordinary count nouns like these, but also nouns whose unmarked forms refer to clusters of items, such as insects and grains, and whose marked forms refer to particular instances of these items, such as an individual insect or grain (Grimm, 2018). In Welsh, for example, cacwn denotes hornets, but cacynen an individual hornet. Yet other languages, such as the Brazilian language Yudja, have only count nouns (Lima, 2018). In Yudja, numeric quantifiers can combine with all nouns, referring to individuated portions in the case of substances (e.g., puddles of water).

The goal of the present study is to examine how the conceptual distinction between objects and substances relates to the grammatical distinction between count and mass nouns (and similar linguistic differences in classifier languages and other languages). There is likely to be a statistical correlation between the two, with count nouns often referring to objects and mass nouns to substances. As we will see, however, many exceptions exist to this tendency, and these exceptions provide possible insight into the relation between the two distinctions. In particular, we can ask what (if anything) the count/mass distinction can tell us about the concepts of objects and substances.

The first section of this article attempts to define the issues with which we will be concerned. Recent evidence makes it clear that infants are sensitive to differences between solid objects and nonsolid substances, and we can therefore ask (a) whether this early conceptual distinction affects learning of count and mass nouns, and (b) whether language plays a causal role in reshaping the concepts of objects and substances. The second section reviews studies of how children first acquire the count/mass distinction. In particular, we ask whether words for typical objects (e.g., balls) are learned as count nouns before words for less typical ones (e.g., bubbles), and whether words for typical substances (e.g., sugar) are learned as mass nouns before words for less typical ones (e.g., bread). The third section takes a closer look at the atypical cases to determine whether mismatches between the conceptual and linguistic distinctions within a language alter the way people think about objects and substances. For example, does the mass noun status of words like clothing and toast that name countable objects affect our concepts of these items? Along similar lines, the fourth section examines crosslanguage studies in search of evidence that differences in the syntactic status of a noun reshape its conceptual status. For example, do speakers of classifier languages think differently about objects than speakers of number-marking languages do? The General Discussion draws some conclusions about what appears to be the causal independence of the key distinctions.

\section{The relation between the mass/count distinction and the substance/object distinction}

Some semantic analyses of count and mass nouns provide a basis for the view that count nouns refer to entities in an ontological domain of objects and mass nouns refer to entities in a separate ontological domain of substances (see Keil, 1979 , for the notion of ontological domain in psychology). Link's (1983) theory of mass terms and plurals, in particular, assumes that count terms, such as an almond (as in Calvin snacked on an almond), denote atomic individuals (an individual almond) in a domain of objects. However, mass terms denote portions in a substance domain with distinct rules of combination. For example, the mud in the sentence Calvin stepped into the mud refers to a quantity (a portion of mud) in the substance domain. Functions map objects in the first domain to portions in the second in order to explain mass uses of count nouns, such as The chef adds almond to the pastry. Although not all linguists buy into a fundamental distinction between object and substance domains (for an alternative, see Chierchia, 2010), the psychological facts surrounding the count/mass distinction may cast light on the plausibility of this semantic framework.

The count/mass distinction may also provide clues about people's underlying concepts of substances and objects. People seem to believe that objects are formed from substances-raw materials like water, wood, or metal. Causal forces apply to these substances and can transform them into objects, maintaining them over their lifetimes. During the lifetime of an object, the constituting substances continue to exist as constituents, although the same object can sometimes add new substances and shed old ones. The same car, for example, can continue to exist over a change in its tires, brakes, and other parts, and the same cat can continue to exist over a change in its component cells. At the end of its lifetime, the sustaining forces dissipate, and the object goes out of existence, although the associated substance continues to exist. In this way, an object at any one time has a kind of double existence as form and matter-an idea traceable to Aristotle (1994), but also found in recent work in metaphysics (e.g., Fine, 1999; Johnston, 2006; Koslicki, 2008; Sattig, 2010) and in linguistic semantics (e.g., Krifka, 1989; Link, 1983).

A substantial body of psychological evidence has examined people's recognition of objects and substances. Evidence from studies of infants suggests that they understand the difference between solid objects and nonsolid substances (see Rips \& Hespos, 2015, for a review). At 2 or 3 months, infants react as if they believed that an object occupies a connected region of space, moves as a whole, and cannot occupy the same place as another object at the same time (e.g., Aguiar \& Baillargeon, 1999; Baillargeon, 1995, 2008; Hespos \& 
Baillargeon, 2001; Spelke, 1990; Spelke, Breinlinger, Macomber, \& Jacobson, 1992). At 5 months, infants react in distinct ways to solid objects and to nonsolid substances. For example, they can grasp the difference between the motion of liquid in a moving glass and the motion of a similar-looking solid in the glass. They can then use that information to predict the behavior of the liquid or the solid when the glass is upended-whether the contents will pour out or tumble out. And they can anticipate what will happen when a solid cylinder is inserted in it - whether the cylinder will remain on top of the contents or pass through them (Hespos, Ferry, Anderson, Hollenbeck, \& Rips, 2016; Hespos, Ferry, \& Rips, 2009). Additionally, 5-month-old infants have expectations about how nonsolid substances accumulate. Infants expect that when a cup of sand pours behind a screen, it will accumulate in one pile, not two (Anderson, Hespos, \& Rips, 2018). Taken together, the infant studies reveal that the object/ substance distinction emerges prior to language acquisition. Instead of language specifying the difference between them, the concepts OBJECT and SUBSTANCE seem linked to mechanisms for representing everyday entities and are likely shared by other animals.

Nevertheless, the evidence does not imply that grammar plays no role in our thinking about objects and substances. Although the findings show that in certain cases infants treat objects differently from substances, this is consistent with the possibility that infants do not yet have the adult concepts OBJECT and SUBSTANCE. Perhaps grammar is critical in establishing these "hyperordinate" concepts. Infants may begin with some clear examples of objects and of substances, but grammar may stake out the concepts' range (as McPherson, 1991, suggests). This possibility may be especially likely for knowledge of solid substances, such as wood and metal. A pure percept of an all-wooden table, for example, cannot distinguish the table from the wood, since any perceived portion of the wood is a perceived portion of the table (and conversely). So, people may need further conceptual resourcesperhaps driven by grammar - to separate them. Similarly, the grammatical difference may bias the way people think about entities that lie on the border of the object/substance domains, such as the aggregates (e.g., hornets), mentioned earlier, that receive special marking in Welsh and other languages (Grimm, 2018).

If the count/mass distinction helps to shape the OBJECT/ SUBSTANCE distinction, one might expect these distinctions to converge in development. Following this convergence to its limit, one might predict that adult speakers would end up with a coextensive pair of distinctions, with count nouns naming all and only objects, and mass nouns naming all and only substances. But, in fact, there are clear exceptions to this equivalence, well documented in linguistics and philosophy of language. These include object mass nouns like cattle, silverware, and jewelry that seem to denote objects rather than substances. So whatever language does by way of transforming the concepts OBJECT and SUBSTANCE, this process cannot be complete, since the distinctions do not coincide, even for adults, and since languages differ in which objects and substances they encode as count or mass. Looking at the exception cases may prove informative, however, since the exceptions may identify instances in which count language gets us to think of a substance as more object-like or instances in which mass language gets us to think of an object as more substance-like. These are the types of cases we focus on here. ${ }^{1}$

An analogy may help clarify the effect we are looking for. People likely believe in a relation between particular countries and particular languages. For example, they know about the difference between France and Germany and between French and German, and they believe in relations between these two distinctions: Among many other things, they know that utterances of French are likely to occur in France, and utterances of German in Germany. This correlation is far from perfect, of course, since many people speak French (German) in places outside France (Germany), but people can use one of these distinctions to make informed guesses about the other, based on the correlation. If they learn that a person is from France (Germany), they may infer that she can speak French (German). And, less confidently, they may infer that if a person is speaking fluent French (German), then she is an inhabitant of France (Germany). But what is less clear is whether knowledge of one of these distinctions alters knowledge of the other. Does a change in people's knowledge about France and Germany (e.g., about the geopolitics of these countries) causally affect their knowledge of French and German? Does a change in their knowledge of French and German (e.g., about their grammar) affect their knowledge of France and Germany? These questions are the analogs of the issues we pursue in this article. There is evidence that beliefs about whether a novel item is an object or a substance affect whether people will use a count noun or a mass noun to describe it (e.g., Hall, 1996; Middleton, Wisniewski, Trindel, \& Imai, 2004; Prasada, Ferenz, \& Haskell, 2002; see Rips \& Hespos, 2015). In addition, use of a count noun (e.g., stones) or a mass noun (e.g., stone) to describe a given object will affect how we interpret a sentence that contains the noun (e.g., Calvin has more stones/stone than Martha; e.g., Barner \& Snedeker, 2005). But it is an open question whether the count/mass distinction affects the concepts OBJECT/SUBSTANCE (or the reverse).

\footnotetext{
${ }^{1}$ Other distinctions among nouns, aside from count versus mass, might also have conceptual reflexes. For example, some nouns (pluralia tantum), such as odds, jeans, and pliers, have only plural forms (*odd, *jean, *plier). Do we think of the referents of such items as somehow being more multiple than those of ordinary count nouns (e.g., probability, skirt, and wrench)? Because our aim is to explore effects on the object/substance difference, we do not pursue these differences here (but see Nickels, Biedermann, Fieder, \& Schiller, 2015, for a proposal about the lexical representation of pluralia tantum).
} 
We begin by briefly reviewing the way children acquire the relevant count/mass distinction, and we then examine the effects of this distinction, both within and across languages. The syntactic difference between count and mass nouns (and among types of classifiers) raises critical issues in psycholinguistics about how they affect online language processing (e.g., Gillon, Kehayia, \& Taler, 1999; see Fieder, Nickels, \& Biedermann, 2014, for a review). Our focus in the present article, though, is on the relation of the count/mass distinction to conceptual rather than to syntactic processing issues. Similarly, because research and theory on this topic in psychology has concentrated on the object and substance concepts of normal first-language learners and adults, we limit attention to these populations. However, a book-length review might also include studies of the mass/count distinction among second-language learners (e.g., Snape, 2008), older adults (e.g., Taler \& Jarema, 2007), and aphasics (e.g., Shapiro, Zurif, Carey, \& Grossman, 1989), among others.

\section{Learning number marking}

If infants start off with initial concepts of (solid) objects and (nonsolid) substances, as we have maintained, then we might expect them to use these concepts to help them learn which nouns are count and which are mass (Strickland, 2017). Children should begin by learning that count nouns denote typical cohesive solid objects, like table and cat, and that mass nouns denote typical noncohesive nonsolid substances, like water and milk. Later, children should adjust the boundaries of these noun classes to include atypical items like bouquet, noodle, and bubble among their count nouns, and clothing, toast, and jewelry among their mass nouns. In these later stages, they should depend less on the referents of the nouns and more on the syntax of the sentences in which those nouns appear. Let us call this hypothesis the typical object/substance advantage in acquisition. But although several studies have looked for such an advantage, little evidence supports its existence.

One test of the typical object/substance advantage comes from simple observation of when children acquire count nouns for typical (vs. atypical) objects, and when they acquire mass nouns for typical (vs. atypical) substances. Nouns for typical items within each domain should be acquired before nouns for atypical items. However, when parents of 17-33month-old children identified the count and mass nouns that these children knew, their lists did not show the expected shift from count nouns that name typical solid objects and mass nouns that name typical nonsolid substances to nouns that show more atypical patterns (see Fig. 8 in Samuelson \& Smith, 1999). Rather, the data show a fairly constant proportion of nouns in these two typical classes relative to the child's total noun vocabulary. Throughout this age range, about $50 \%$ of all nouns are count nouns for solid things, and 5\% are mass nouns for nonsolids. (Most of the remaining 45\% were classified by adults as ambiguous in syntax, e.g., cake and tissue, or ambiguous in solidity, e.g., pillow and butter.) Although there is a reduction in the variability of these proportions, there is no overall decrease.

Experimental studies likewise fail to show the typical object/substance advantage in learning count nouns for solid cohesive things (and mass nouns for nonsolid noncohesive ones) over more atypical combinations. In one procedure (Gathercole, 1985), 3.5-9-year-old children judged the correctness of the speech of a puppet whose noun phrases varied in whether they contained count or mass quantifiers (many vs. $m u c h$ ), singular or plural endings, and typical or atypical count and mass nouns. The nouns could be count nouns for typical objects (e.g., boy), count nouns for atypical objects (e.g., noodle), mass nouns for typical substances (e.g., water), and mass nouns for atypical substances (e.g., bread), among others. $^{2}$ For example, the puppet's sentences could take the forms of those in (1), where asterisks indicate nouns that make the resulting sentence ungrammatical:

(1) a. Big Bird saw many (*boy) / (*noodle) / (*water) / (*bread).

b. Big Bird saw much (*boy) / (*noodle) / (water) / (bread).

c. Big Bird saw many (boys) / (noodles) / (*waters) / (*breads).

d. Big Bird saw much (*boys) / (*noodles) / (*waters) / (*breads).

Children's accuracy in judging the correctness of the sentences improved with age (from $44 \%$ correct for 3.5 -year-olds to $73 \%$ correct for 8.5 -year-olds). However, they were no more accurate for the typical nouns (64.5\% correct) than for the atypical ones (65.4\%) overall (Gathercole, 1985, Table 2).

The same message - learning the count or mass status of a noun depends more strongly on its syntactic context than on the nature of its referent - comes from a production task with 3-6-year-olds (Gordon, 1985). The participants saw examples of unfamiliar solid objects (e.g., electrical components) or unfamiliar nonsolids (unfamiliar liquids in test tubes). The experimenter named these items using count or mass syntax

\footnotetext{
${ }^{2}$ Typical count nouns were ones that "typically occur with count quantifiers and which refer to objects that have heterogeneous make-up and come in individuated units that constitute minimal parts"; atypical count nouns were ones that "typically occur with count quantifiers but which refer to objects with homogeneous make-up and which could be broken up in such a way that one could still refer to the remainder with the same noun"; typical mass nouns were ones that "typically occur with mass quantifiers and which refer to objects that are homogeneous and have no discernible minimal parts"; and atypical mass nouns were ones that "typically occur with mass quantifiers but which refer to objects that typically come in individuated, countable pieces" (Gathercole, 1985, p. 491).
} 
("This is a/some cheem"), and then asked the participants to name further examples of the same items: "Over there we have more ... what?" The participants' responses depended more on the quantifier ("a cheem" prompted "more cheems," and "some cheem" prompted "more cheem") than on the object/substance status of the examples. Participants were able to use the object or substance cue to decide their response (e.g., when no syntactic information was present), but it was not the dominant influence. Similarly, although the data hint that the object/substance difference played a larger role in the productions of the younger than the older participants, both groups relied more heavily on the quantifiers (see Fig. 1 of Gordon, 1985).

These results suggest, then, that children learn which nouns are count and which mass through a process that does not strongly depend on the difference between their OBJECT and SUBSTANCE concepts. Although the count/mass and OBJECT/SUBSTANCE distinctions are correlated statistically in children's experience - at least, children's vocabulary shows a significant relation between count/mass and solidity/ nonsolidity (Samuelson \& Smith, 1999) - little evidence exists for a more substantive, psychological relation between them. Of course, we should keep in mind that any conclusions about the psychological independence of the count/mass and OBJECT/SUBSTANCE distinctions are provisional, and further evidence (e.g., with younger children) may establish a substantive link between them. But we will see that the independence verdict is repeated in other situations where these distinctions come in contact. The independence between the conceptual distinction and the grammatical is reminiscent of the development of semantic spatial categories (Hespos \& Spelke, 2004; McDonough, Choi, \& Mandler, 2003). For spatial categories (e.g., support, containment, the difference between a tight fit and a loose fit between two objects), the conceptual distinctions are evident prior to language (Casasola \& Cohen, 2002), as with the OBJECT/SUBSTANCE distinction (Hespos et al., 2016; Hespos et al., 2009). Similarly, there are cross-linguistic differences in how the children describe identical physical relations, as with the mass/count variations across languages (Bowerman, 1996; Choi \& Bowerman, 1991). We note, too, that independence between the two distinctions is consistent with changes in children's notions of objects and substances (e.g., Au, 1994; Dickinson, 1987; Rosen \& Rozin, 1993) and in their knowledge of the mass/count distinction (e.g., Gathercole, 1985; Gordon, 1985).

\section{Effects of intralanguage grammatical differences on the substance/object distinction}

Count nouns typically refer to types of objects, and mass nouns to types of substances. Cat and toaster, for example, name object types, but mud and gold name substance types. Effects of the grammatical count/mass distinction on our concepts of objects and substances will not show up under this normal assignment because the grammatical and semantic properties are confounded. An opening for investigation, however, comes from situations in which the syntactic and semantic distinctions do not completely coincide. This section looks at two cases of this sort of slippage. In the first of them, nouns that are ordinarily count are used as mass, or nouns that are ordinarily mass are used as count. If the count/mass distinction causes us to think differently about the referents of these nouns, we should find evidence that people reconstrue the referents in these situations. The second case involves object mass nouns (e.g., cattle, pottery). Although these nouns name things we can count (heads of cattle or pieces of pottery), their mass noun syntax may require us to conceive of them differently than similar items named by count nouns (cows, pots).

\section{Coercion}

If there is a broad conceptual difference between objects and substances, then shifting from one domain to the other should require cognitive resources. People may have at least momentary difficulty reconceptualizing a particular object as the substance that constitutes it or reconceptualizing a bit of substance as the object it constitutes. For example, it may take time and effort to switch from thinking of a statue to thinking of the brass that constitutes it, and similarly, from thinking of a piece of brass to thinking of the statue that it constitutes. One place to look for such effects is in sentences that force a substance interpretation on a count noun or an object interpretation on a mass noun. Calvin put carrot in the stew, for example, uses carrot - normally a singular count noun - in a context where it appears without a determiner. Because singular count nouns typically occur only after determiners (Martha pulled a carrot from the garden), the bare, determiner-less context forces or coerces a substance reading. Calvin put carrot in the stew means that he put a quantity of carrot, rather than an individual carrot, in the stew. As we noted earlier, Link (1983) suggests that we can think of this reinterpretation as a mapping from the object to the substance domain - from an individual object or a set of objects to the substance that composes them-a process sometimes called grinding. In the reverse direction, mass nouns can appear in contexts that coerce an object reading. Martha drank two whiskeys uses a mass noun, whiskey, with a plural marker and a numeric quantifier, which are normally reserved for count nouns. This suggests that she drank two glasses of whiskey. Coercion of this latter sort is more likely when the substance comes in standard portions, such as glasses. For example, Calvin stepped in three muds is understandable but less good than Martha drank two whiskeys. Reinterpreting mass nouns in this way corresponds 
to mapping from the substance domain to the object domain, and this conceptual packaging or portioning may be easier when object slots (e.g., glasses of whiskey) already exist for the substance.

We would expect coercion to make sentence understanding more difficult because of the extra work or uncertainty involved in the mapping process. Possible evidence for this cost comes from a study by Frisson and Frazier (2005), comparing sentences such as $(2 \mathrm{a}-\mathrm{d})$ :

(2) a. Yesterday, Melissa tasted inexpensive clam at the local supermarket.

b. Yesterday, Melissa tasted inexpensive cola at the local supermarket.

c. Yesterday, Melissa tasted a spoonful of inexpensive clam at the local supermarket.

d. Yesterday, Melissa tasted a spoonful of inexpensive cola at the local supermarket.

Because singular count nouns like clam normally do not appear without a determiner, $(2 \mathrm{a})$ requires a grinding reinterpretation. Mass nouns like cola, though, usually do not take determiners; so readers can interpret (2b) without extra processing. The prediction is therefore longer reading times for (2a) than (2b). However, preceding the critical adjective and noun with a pseudopartitive like a spoonful of, as in (2c-d), should warn readers that reference to a substance might follow, reducing the difficulty of $(2 \mathrm{c})$ relative to $(2 \mathrm{~d})$. In line with these predictions, Frisson and Frazier found in an eye-tracking experiment that readers looked longer at the region following the critical noun in sentences like (2a) than in those like $(2 b-$ d). A comparable experiment examining coercion from mass to count (e.g., This morning Melissa sampled inexpensive cokes at the local Stop and Shop) found analogous but smaller effects. But as Frisson and Frazier point out for the mass-tocount case, the difficulty readers have with the coerced sentences could either be due to the reconstrual or to the grammatical clash (e.g., clam appearing without a determiner, coke appearing with a plural marker). For example, readers may be more accustomed to interpreting constructions like (2b) than ones like (2a). To find the source of the effect, we need to know if (and how) reinterpretation occurred.

\section{Object mass nouns}

A second place to look for effects of the grammatical count/ mass distinction is in the way people deal with nouns like ammunition, toast, clothing, furniture, jewelry, luggage, pottery, cutlery, cattle, change, silverware, and underwear. These nouns seem to denote objects yet are syntactically mass nouns. Cutlery, for example, applies to roughly the same things as forks, spoons, and knives, and furniture to the same things as tables, chairs, and beds. The same is true of minimal mass/ count pairs such as clothing and garments, cattle and cows, pottery and pots, and change and coins. The first elements of these pairs are object mass nouns or fake mass nouns, and they seem to denote the same items as the paired count nouns. Object mass nouns more commonly denote superordinate categories (e.g., furniture, clothing) than basic level categories (tables, shirts) across languages (Markman, 1985). ${ }^{3}$ However, object mass nouns are somewhat unstable: The closest translation for one language's object mass noun may be another language's count noun. Furniture is mass in English, but les meubles is count in French; dishes is count in English, whereas la vaisselle is mass in French (to cite some examples from Gillon, 2012).

Object mass nouns, like ordinary mass nouns, cannot occur with numeric quantifiers. Sentences like *Calvin put three silverware(s) in the dishwasher are not possible; so silverware cannot be grammatically counted (Rothstein, 2010). Nevertheless, we can count the referents of silverware in the same way we can count knives, forks, and spoons. For ordinary mass nouns, such as ketchup or toothpaste, however, we usually cannot count their referents. Although we can determine how much ketchup or toothpaste exists in a given place, we cannot assess how many there are, without the support of external context (e.g., in a situation in which a waitress wants to know how many packets of ketchup to bring to a table). Evidence for the countability of object mass nouns comes from a study by Barner and Snedeker (2005). These investigators showed participants (4-year-olds and adults) pictures of three small instances of an object mass noun and one large instance whose area was bigger than the total area of the small ones. For example, participants saw three small examples of silverware (three small forks) and one large example (one large fork). Participants received scenarios in which one character had the three small examples and another character had the large one. The participants then answered the question, Who has more [e.g., silverware]? The results showed clearly that both adults and children pick the character who has more pieces (e.g., three forks) rather than the one with more area. This choice contrasted with that for true mass nouns. Asked Who has more ketchup? for three small blobs versus one large blob of ketchup, participants consistently chose the large blob. Thus, object mass nouns denote entities with properties that make it possible to enumerate them (see Barner, Wagner, \& Snedeker, 2008, for parallel findings with deverbal mass nouns like jumping in sentences like Who did more jumping?; and Bale \& Barner, 2009, and Wellwood, Hacquard, \& Pancheva, 2012, for formal attempts to account for these facts about comparatives).

\footnotetext{
${ }^{3}$ But see Takatori and Schwanenflugel (1992) for qualifications. Some languages - such as Hungarian - have many nouns (e.g., könyv, "book") that can function as either object mass nouns or as count nouns (see Rothstein, 2017).
} 
Both object mass nouns and ordinary count nouns seem to denote countable objects. So differences in the way people think about the referents of these two types of noun may reveal effects of purely linguistic factors on object concepts. For instance, both object mass nouns and ordinary count nouns can name superordinate categories of physical objects: Vehicle and dwelling are count noun superordinates, but furniture and clothing are mass superordinates. We might take advantage of this fact to look for cases in which the existence of a mass superordinate (vs. a count superordinate) changes the way people conceive of members of these categories. Perhaps application of a mass noun imposes substance-like properties (e.g., lack of atomic structure, thus blocking individuation) in the way people think about its referent, extending the boundary between the object/substance domains to allow more entities to be substances. In fact, evidence suggests people believe that members of mass superordinates co-occur more often in experience than those of count superordinates (Wisniewski, Imai, \& Casey, 1996; Wisniewski, Lamb, \& Middleton, 2003). For example, people judge that two pieces of furniture (e.g., a chair and a table) occur together more often than two animals (e.g., a lion and a tiger) do. Similarly, people believe that they are more likely to interact with multiple instances of mass superordinates (e.g., in washing clothing) than to interact with multiple instances of count superordinates (e.g., in watering plants). Grimm and Levin (2012) also suggest that the referents of object mass nouns are often artifacts that participate as a heterogeneous group in some event. Clothing, for example, consists of shirts, skirts, trousers, and other items usually involved in dressing and undressing. However, although these findings suggest conceptual differences between count and object-mass superordinates - which was what Wisniewski et al. set out to show-they do not suffice to demonstrate that the linguistic distinction affects the conceptual one. Instead, facts about the categories may be influencing the likelihood (over historical time) that they will be lexicalized as mass or count (see also Wierzbicka, 1988).

Evidence for a directional effect of the count/mass distinction on superordinate concepts comes from an experiment by Markman (1985), who taught 3-year-olds and 4-year-olds superordinate categories using either count or mass syntax. Participants saw pictures of items from such a category-for example, a picture of a racquet, a helmet, a hockey stick, and a mitt from the category sports equipment - and the experimenter referred to them either with count phrases ("These are vebs," "A helmet is a veb," "How many vebs are here?") or mass phrases ("These are pieces of veb," "A helmet is a piece of veb," "How much veb is here?"). Participants then had to discriminate new instances of the category (e.g., a bat or a soccer ball) from noninstances (e.g., a pencil or a hat). Participants performed better at test if they had learned the categories with mass nouns than if they had learned them with count nouns. Of course, if the children in this study had already known the meaning of some object mass superordinates, they could have used these meanings to help them understand the category. For example, if they realized that object mass superordinates often denote artifacts that appear together in an activity, they could have taken the mass syntax as a hint that $v e b$ refers to objects used in sports. But children of this age probably are not familiar with a large enough set of object mass superordinates to allow them to possess such a generalization.

Markman (1985) suggests instead that mass syntax employs a relation, X IS A PIECE OF Y, which is distinct from the more usual membership relation for categories, X IS A Y. The new relation helps children see that a particular object can simultaneously be a member of a basic level category (e.g., that a particular helmet "is a helmet") and of a superordinate category (that the same helmet "is a piece of sports equipment"). This change in relation sidesteps children's tendency to believe that an object can have only one valid label (e.g., either helmet or sports equipment, but not both) - the mutual exclusivity constraint - and simplifies learning for that reason. This explanation leaves open, though, whether the benefit in learning superordinates as mass nouns is due to the distinctness of the expression for the relation (the linguistic expression "is a piece of") or to the distinctness of the expression's meaning (the relation IS A PIECE OF itself). If the concept IS A PIECE OF is responsible for the effect, children would have to possess this concept before they could apply it in the categorization task. However, the most relevant sense of the relation in this context would seem to be the same as (or very similar to) IS A. If children understood "is a piece of" in this way, it is unclear how it could get around the mutual exclusivity constraint. Children of this age are also unlikely to know other meanings for "is a piece of" that would do a better job of explaining the data, as we noted in the previous paragraph (see Sera \& Goodrich, 2010, for evidence on children's understanding of a piece of). ${ }^{4}$ This suggests that it is the syntax of the phrase, rather than the meaning of the relation, that is responsible for the advantage in learning.

\section{Summary}

Constructions with object mass nouns, sentences with coercion, and similar phenomena provide opportunities to demonstrate linguistic effects on people's concepts of substances and objects. Using a mass noun to label an object or using a count

\footnotetext{
${ }^{4}$ The relevant concept for "is a piece of" in this context cannot be the same as IS A PORTION OF, since children presumably do not believe that $A$ helmet is a piece of veb means that a helmet is a chunk of some substance veb (on an analogy with A puddle is a portion of liquid). What substance could constitute racquets, helmets, hockey sticks, and mitts, but not hats or pencils? Likewise, children probably do not interpret $A$ helmet is a piece of veb as meaning that the helmet is a part of some larger object (as in You may have one piece of cake), since a helmet is not a physical part of any ordinary object.
} 
noun to label a substance could change the way we think about the object or the substance. Current evidence, however, provides little support for such effects. In some cases, the consequences of these clashes may be due to syntax alone. The benefit of learning to categorize objects with mass nouns may be due to the novel mass syntax (e.g., this is a piece of blicket) evading interference from the typical count syntax (e.g., this is a blicket). In other cases, the choice of count or mass constructions may follow from the special conceptual properties of objects or substances rather than the other way around.

\section{Effects of cross-language grammatical differences on the substance/object distinction}

We can also look for effects of the count/mass distinction on concepts of objects and substances by taking advantage of cases in which one language uses a count noun to name an entity while a second language uses a mass noun. In addition to the English-French examples mentioned earlier, jewelry and kitchenware are mass in English, but their counterparts, korut and keittiövälineet, are count in Finnish (Sutton \& Filip, 2016b). Perhaps the use of the mass version of one such pair (e.g., jewelry) will lead English speakers to think of the items as more substance-like, and use of the count version (e.g., $k o r u t$ ) will lead Finnish speakers to think of the item as more object-like.

\section{The generalization method}

Most of the experiments that have looked at these crosslanguage effects have employed a generalization technique in which participants see a labeled example of a particular item and must then decide whether the label also applies to an item with the same shape as (but different substance than) the original or to one with the same substance (but different shape). For example, participants may hear a nonsense noun (e.g., This is my fitch) applied to a copper plumbers' tee fitting and may then be asked whether the noun (fitch) also applies to a plastic tee fitting or to three irregular pieces of copper (e.g., Dickinson, 1988; Soja, Carey, \& Spelke, 1991). Similarly, the noun could be applied to an S-shaped blob of hair gel, with the participant asked to decide whether the label is also appropriate for an S-shaped blob of hand cream or a Cshaped blob of hair gel. We will call the original example the standard, and the two options the targets. This procedure does not require that the experimenter use a noun that the participant can identify as mass or count. The sentences can be uninformative: In This is my fitch and Point to the fitch, fitch could be either mass or count (cf. This is my water/clock, Point to the water/clock). However, the sentences can also be informative: Experimenters can use mass syntax (This is fitch) or count syntax (This is a fitch) to determine whether the syntax affects participants' choice in this paradigm.

Figure 1 (based on Rips \& Hespos, 2015) summarizes the results from some studies of this type that use comparable methods with adults (Panel a) and 2-year-olds (Panel b). These studies did not use informative (count or mass) syntax, either in the initial labeling or in the instructions, to point to the instance with the same label; so they provide a type of baseline for language effects. ${ }^{5}$ The $x$-axes indicate whether the standard stimulus from these studies was a complex solid (e.g., a plumber's copper tee fitting), a simple solid (e.g., a kidney-shaped wad of wax), a complex nonsolid (e.g., an Sshaped blob of hair gel), and in the case of the 2-year-old's data, a simple nonsolid (e.g., a smear of frosting). The $y$-axis is the proportion of trials participants chose the same-shape target over the same-material target. Although the data are variable across studies, the trend shows that both adults and children are more likely to generalize the name for solid, complex objects to same-shape targets than to same-material targets, and more likely to generalize the name for simple nonsolid substances to same-material targets than to same-shape targets. Simple solids and complex nonsolids fall in between. These studies did not produce strong effects of whether the experimenter labels the standard with an uninformative noun (This is my fitch; point to the fitch) or an uninformative demonstrative (Look at this; which is the same?). Solid black lines in the figure indicate the former instructions, and dashed red lines indicate the latter. Other studies, however, suggest that 3-year-olds adopt a default generalization by shape unless a noun (informative or uninformative) is present (Subrahmanyam, Landau, \& Gelman, 1999). ${ }^{6}$

Informative syntax modulates these results, especially for older participants. Labeling the solid object with a count noun or the nonsolid object with a mass noun does not change the performance of 2-year-olds, relative to uninformative labeling (Soja et al., 1991). However, labeling the solid object with a mass noun leads to fewer same-shape choices, and labeling the nonsolid object with a count noun leads to more same-

\footnotetext{
${ }^{5}$ The experiments in this figure are drawn from those obtained by searching PsycInfo with the keywords "substance" and "noun" and the keywords "mass" and "noun." We have omitted experiments that did not test either adults or 2-year-olds (e.g., Dickinson, 1988; Gathercole \& Min, 1997), experiments that asked participants to decide whether a single entity should be labeled with a mass or count noun (e.g., Hall, 1996; Middleton et al., 2004; Prasada et al., 2002), and those in which the experimenter labeled the standard object with a mass or count noun (e.g., this is a blicket; this is blicket; e.g., Soja, 1992; Subrahmanyam et al., 1999). We discussed experiments in which participants must produce a count or mass noun in Rips and Hespos (2015), and we will discuss experiments in which the experimenter labels the standard with a count or mass noun momentarily.

${ }^{6}$ As we have noted (Rips \& Hespos, 2015), the exception to the decreasing trend in Fig. 1a comes from Li et al. (2009, Experiment 2). These investigators used standards whose shapes were highly amorphous items. Participants' choices were near chance for complex solids, simple solids, and nonsolids alike.
} 
a Adults

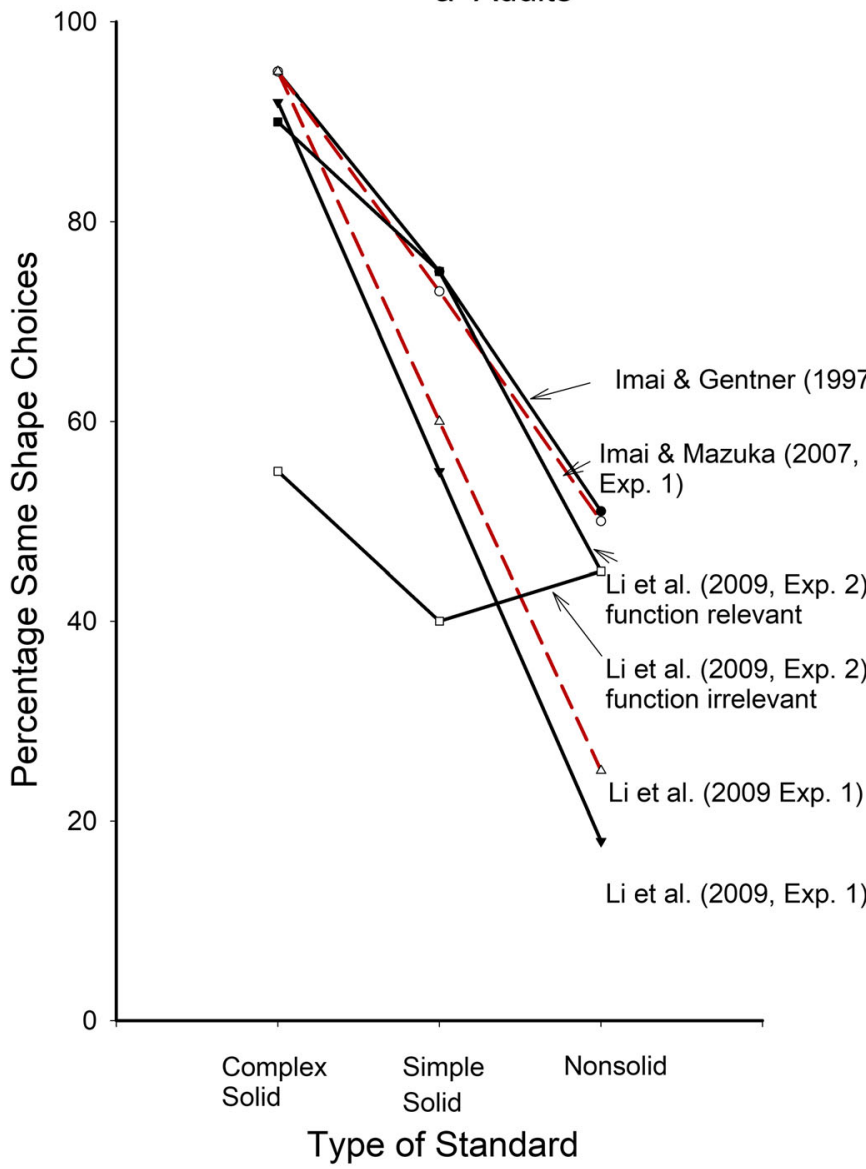

Fig. 1 Summary of results from studies of how adults (a) and 2-year-olds (b) generalize from objects of different types (complex solids, simple solids, complex nonsolids, or simple nonsolids) to a second object with the same shape (in preference to a second object with the same substance). Solid black lines indicate labeling with an uninformative noun (This is my snarb; point to the snarb) and dashed red lines indicate

shape choices for 2-year-olds, effectively flattening the curves in Fig. 1b (Soja, 1992). For adults, the same manipulation reverses the slope of the curves in Fig. 1a: Labeling a solid object with a mass noun leads adults to deny that the noun applies to a same-shape target, and labeling a nonsolid object with a count noun leads them to affirm that the noun applies to a same-shape target (Subrahmanyam et al., 1999). Thus, informative syntax can influence how older children and adults perform on the generalization task.

\section{Effects of the count/mass distinction across languages}

Many of these same experiments have compared the choices of speakers of different languages to check for effects of language on concepts. Speakers of number-marking languages, such as English or Russian, may divide objects and substances differently than do speakers of classifier languages, such as Chinese or Nahuatl, or speakers of languages with only count nouns, such as Yudja.

\section{b Two-year-olds}

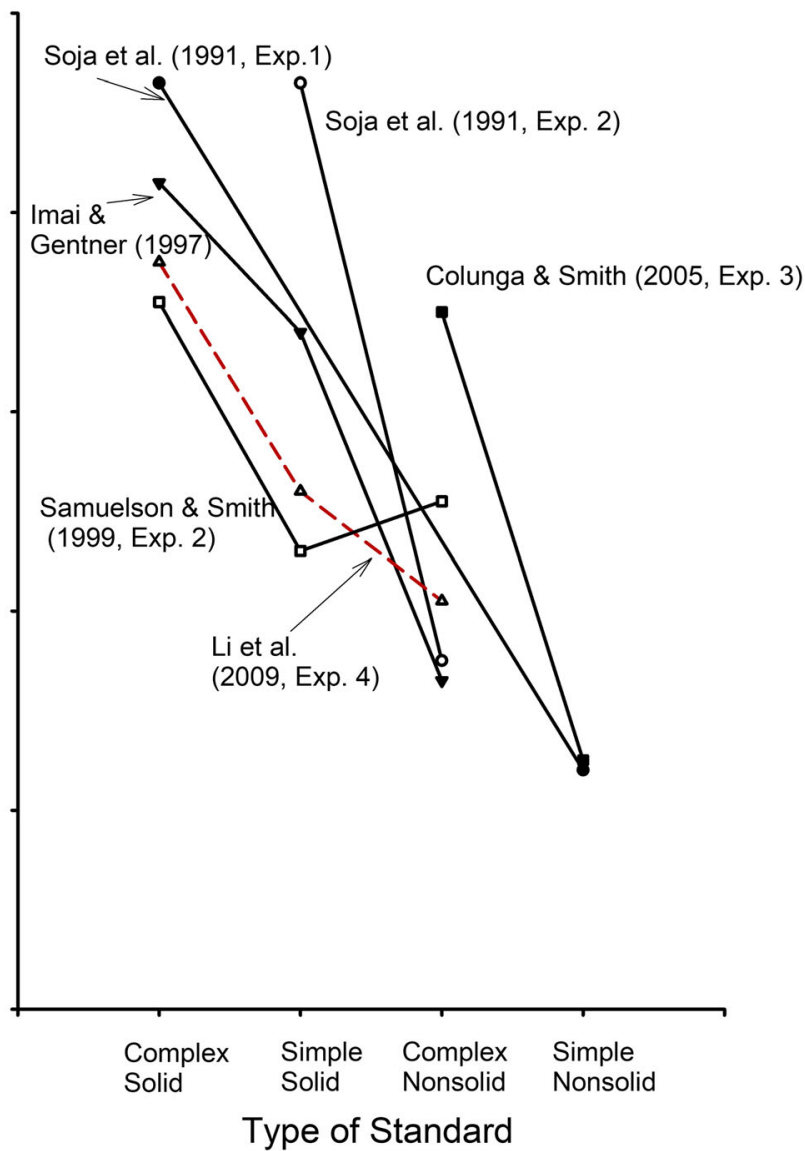

labeling with an uninformative demonstrative (Look at this; which is the same?). Function-relevant items are those judged to have a shape relevant to their function; function-irrelevant items have amorphous shapes not relevant to their function. Modified from Rips and Hespos (2015). (Color figure online)

Within the present framework, possible language effects are easiest to understand as shifts of the boundary between the object and substance domains, as we suggested in the case of some uses of object mass noun superordinates. Some entities may be borderline cases in this framework (Allan, 1980; Grimm, 2018; Sutton \& Filip, 2016a, 2016b). For example, Grimm (2018) argues for four "types of individuation," ranging from liquids and substances (e.g., water, steel) to granular aggregates (e.g., sand, dust) to collective aggregates (e.g., ants, grapes) to full-fledged individuals (e.g., people, toasters). The intermediate categories in this ordering, granular and collective aggregates, are most likely to vary in their grammatical encoding across languages. Perhaps treating these entities linguistically in the same way as clear-cut objects may lead speakers of such languages to attribute to them the same formal properties that objects have, whereas treating them in the same way as clear-cut substances may lead speaker to attribute substance properties. 
One hypothesis along these lines starts from the assumption that all nouns in classifier languages are mass nouns. Just as mass nouns in English require a classifier-like phrase to support numerical quantifiers (e.g., two piles of sand, three puddles of water), all nouns in classifier languages do. Suppose, too, that mass nouns tend to be associated with substances. Then it is possible that speakers of classifier languages will treat entities as substances more often than will speakers of number-marking languages. In the generalization task, for instance, they may be more likely to choose the samematerial target than the same-shape target overall. A more refined version of this hypothesis limits this tendency to borderline cases. Grammatical differences may not affect clearcut exemplars of substance or object concepts - these may fall under conceptual universals - but grammar may influence whether people think of intermediate entities as object-like or substance-like (Imai \& Gentner, 1997). The position of the substance/object boundary for speakers of classifier languages would allow more things to be substances than it would for speakers of number-marking languages.

Evidence from the generalization task Figure 2 summarizes some evidence for these assumptions. The figure compares the percentage of same-shape choices in the generalization task by adult speakers of English and by adult speakers of Japanese (Fig. 2a-b) and Mandarin (Fig. 2c). The first study (Imai \& Gentner, 1997) and the third (Li, Dunham, \& Carey, 2009) used uninformative syntax to label the standard item: The syntax did not reveal the mass/count status of the noun ("Look at this snarb" and its equivalent in Japanese or Mandarin). Participants then had to "Point to the tray that also has the snarb on it." The second of the studies (Imai \& Mazuka, 2007) used instructions that did not include common nouns ("Look at this. Which is the same?"). This difference in phrasing has little effect on participants' choices. The figure shows that English speakers, more often than Japanese or Mandarin speakers, favor the same-shape choice over the same-material choice. However, this difference tends to be smaller when the standard is a complex entity (e.g., a metal whisk) than when it is a simple entity (e.g., a cork bottle stopper) or a nonsolid (e.g., an $\Omega$-shaped pile of sawdust). (For the English-Mandarin comparison in Panel c, the difference is also small for nonsolids, perhaps because of a floor effect.) These data confirm the prediction that speakers of classifier languages favor the samematerial choice, in line with the mass-like properties of their nouns. We will see, however, that a range of interpretations may exist for this effect. ${ }^{7}$

\footnotetext{
${ }^{7}$ We have omitted from Fig. 2 cross-language studies (e.g., Lucy \& Gaskins, 2003) that have not used all of the $x$-axis categories: complex solids, simple solids, and nonsolids.
}

Two models of object/substance generalization Two mathematical models of the generalization task may help explain the facts about substances and objects that we have reviewed. Let us consider first a connectionist theory proposed by Colunga and Smith (2005) and illustrated in Fig. 3. The main idea is that children's performance on this task can be modeled by a neural network that learns to associate names of categories (e.g., "ball," "sand") with properties of the named items that covary in shape, material, and solidity. Input to the simulation are items - word, solidity, shape, and material quartetsbased on the actual noun vocabulary of 3-year-olds and that preserve the observed correlations among these variables. The word layer of the model is shown at the top of Fig. 3 and contains one node for each represented word. The perceptual layer appears at the bottom of Fig. 3. It uses a distributed representation for the shape and material properties, but a localist representation (solid or nonsolid) for solidity. The model also has a set of hidden nodes allowing the network to recognize the correlations among the word and perceptual variables. Simultaneous activation of the word, shape, material, and solidity nodes during learning produces a distinctive pattern of activation over the hidden nodes by means of the associative connections that run between and within the three layers (Fig. 3 shows only a few of these connections). After training on these items, the hidden nodes come to represent a new solid thing as more similar to another item of the same shape than to another item of the same material, and they represent a nonsolid thing as more similar to an item with the same material than to one with the same shape. This mimics the trend in the generalization results, discussed earlier (see Fig. 1). The simulation also learns what Colunga and Smith call an "ontology bias," a tendency to think that referents of nouns are alike with respect to solidity (e.g., balls are solid and sand nonsolid).

To model the cross-linguistic results (see Fig. 2), Colunga and Smith (2005) find that they also need to include in the network a representation of the count/mass status of the words, shown at the bottom right of Fig. 3. That is, the extended network computes the correlation between count/mass nouns, solidity, shape, and material from the input. This extra information helps account for English speakers' tendency to generalize by shape for simple solid items (compared to Japanese-speakers' choices): "Our simulations suggest that the count syntax correlations available to English speakers push them to view simply shaped solids as more like complexly shaped solids than like nonsolids" (Colunga \& Smith, 2005, p. 376).

One question, then, is whether the model is consistent with results from other tasks that we have reviewed. As Colunga and Smith (2005) note, learned associations in this framework are bidirectional. So one might expect children to use information about solidity or shape to predict count or mass syntax. As we noted earlier, adults recognize these regularities, 
a

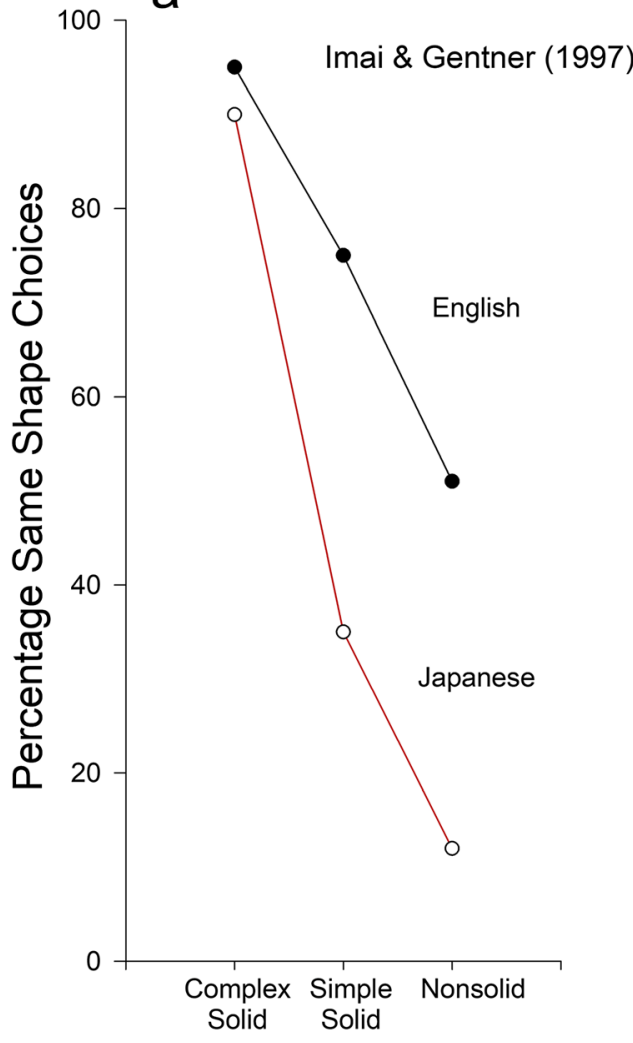

b

C

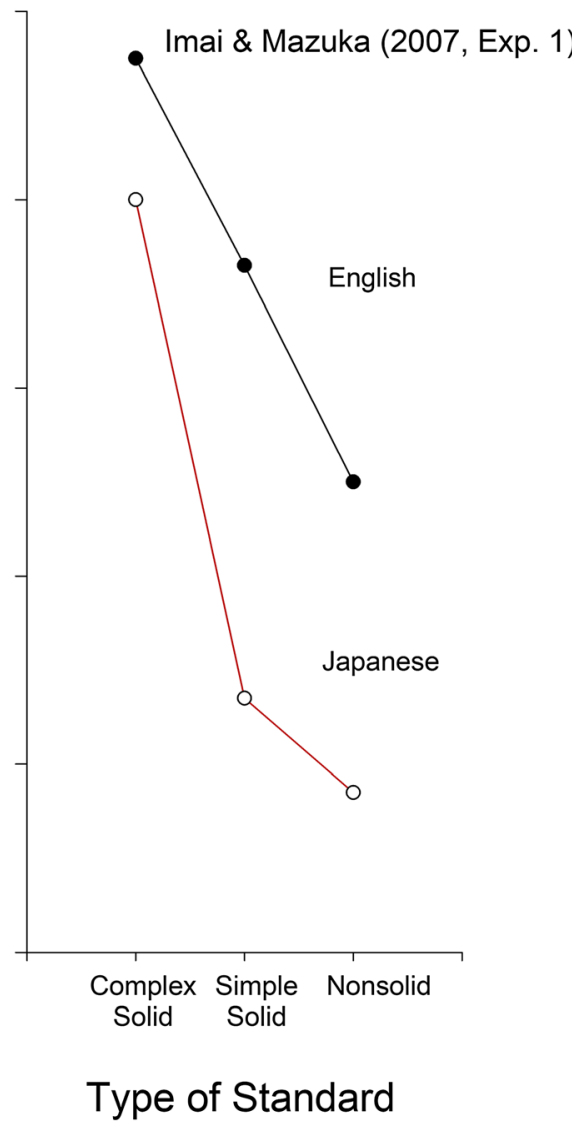

Li et al. (2009, Exp. 1)

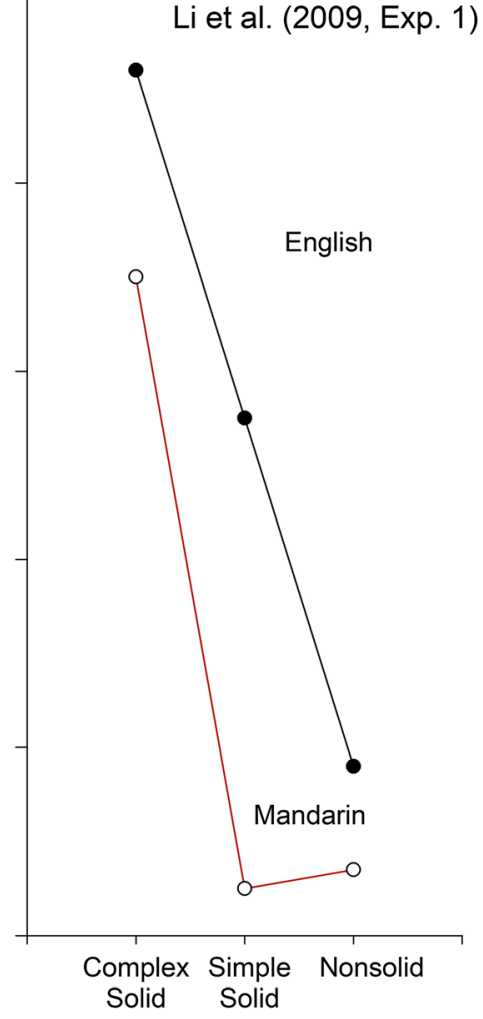

Fig. 2 Summary of results from cross-linguistic studies of how adults generalize from entities of different types (complex solids, simple solids, or simple nonsolids) to a second entity with the same shape (in preference to a second entity with the same substance). (Color figure online)

preferring to label unfamiliar solid and unfamiliar but regularly shaped items with count nouns, and nonsolid and irregularly shaped items with mass nouns (Hall, 1996; Prasada et al.,
2002; see Rips \& Hespos, 2015, for a review). But the Gathercole (1985) and Gordon (1985) findings appear to show that children's grammaticality judgments do not seem

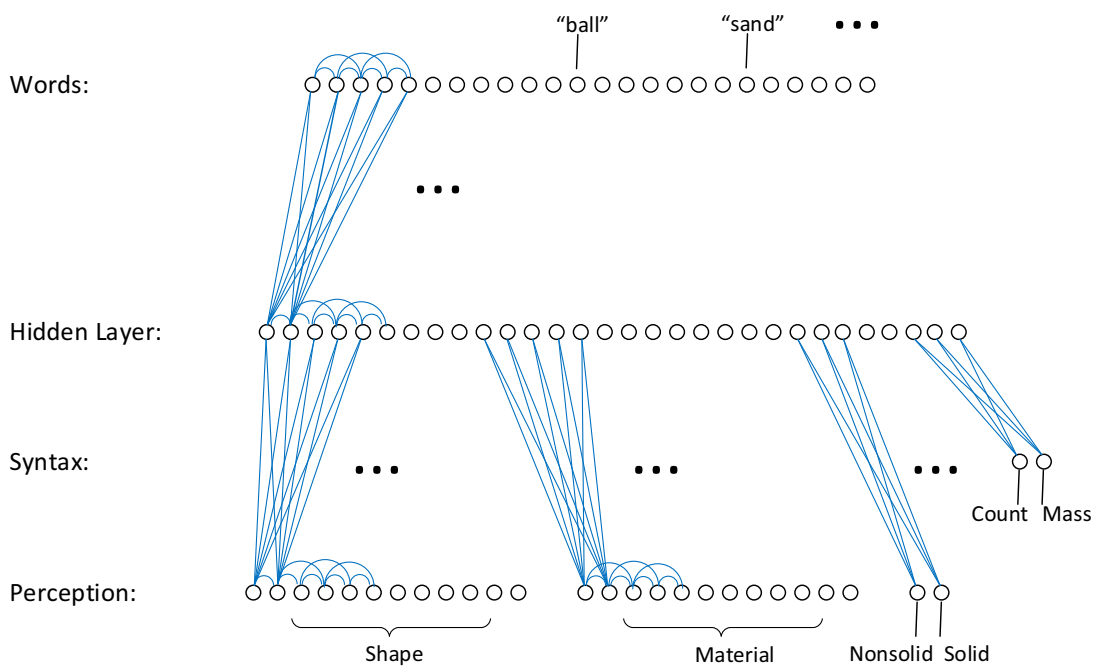

Fig. 3 A connectionist model for learning the association between individual nouns (e.g., "ball") and the shape, material, and solidity properties of their referents, based on Colunga and Smith (2005, Fig.
27). The figure shows only a few of the connections that run between and within levels. See text for a more detailed description 
much affected by the referents of the nouns they learn. One might think that if English-speaking children are simply learning a correlation among count syntax, solidity, and shape (or mass syntax, nonsolidity, and material), then their grammaticality judgments for sentences like (1a-d) would be better for nouns that respect the correlation (e.g., better for count nouns for solid items than for count nouns for nonsolid ones). But this is not the case. So on the one hand, grammatical properties seem to be important in explaining children's classifications of "simply-shaped solids" in the generalization task. But, on the other hand, there does not seem to be any effect of object properties on their grammaticality judgments. Is it that it is a one-way effect, with grammar influencing category formation, but not the other way round? If so, this asymmetry poses a problem for pure (bidirectional) associative learners.

We can also ask how much light the model sheds on concepts of objects and substances. Colunga and Smith (2005) address this issue at the end of their paper, and they consider two possibilities. One is that the object/substance distinction simply coincides with the type of correlational structure that the network learns. Objects just are solid, consistently shaped items named by count nouns, and substances just are nonsolid items with consistent material named by mass nouns. But this seems unlikely given the fact that we easily classify as substances an enormous number of items that break this correlational pattern - for example, solid substances like iron, gold, copper, and wood. More likely (in our view) is Colunga and Smith's second possibility - that the object/substance distinction is about countability rather than about the type of category-based properties (solid/nonsolid, shape-relevant/ shape-irrelevant, material-relevant/material-irrelevant) that the network learns and that drives performance in the generalization task. This possibility accords with the fact that objects often have discrete and stable units that enable them to be counted, while substances tend not to have such units. And in this way, the possibility also agrees with linguistic analyses like those of Krifka (1989) and Link (1983), mentioned earlier. However, this hypothesis leads to the conclusion that the generalization task might not be the best way to examine people's ideas about objects and substances. The generalization task depends on knowledge of the solidity-shape and nonsolidity-material correlations, but the object/substance distinction is a matter of the atomic (i.e., individuated) structure of these domains (atomic in the case of objects and nonatomic in the case of substances).

The second model of interest takes the form of a hierarchical Bayesian theory of the same domain by Kemp, Perfors, and Tenenbaum (2007). Kemp et al. complain that connectionist models like Colunga and Smith's (2005) make it difficult to analyze the distinct levels of knowledge the models acquire, and they propose instead a theory with different degrees of abstraction. Figure 4 pictures these levels. In the case of the generalization task, the model includes a representation of the statistical distribution for particular categories' properties (e.g., the distribution among members of object category $o_{1}$ of their shapes, materials, colors, sizes, and so on; the distribution among members of substance category $s_{1}$ of these same dimensions). These distributions are represented by the $\theta_{\mathrm{oi}}$ for each object category $o_{i}$ and the $\theta_{\mathrm{sj}}$ for each substance category $s_{j}$. At a higher level, the model also has a representation for types of categories, specifying for each type the variability of the properties for categories of that type and the overall distribution of members across all categories of that type. For example, if there are two types of categories, object and substance categories, the model includes information about how variable the object categories are with respect to their shapes, materials, and so on ( $\alpha_{o}$ in Fig. 4$)$, and how variable the substance categories are with respect to the same properties $\left(\alpha_{\mathrm{s}}\right)$. The model also includes information about the distribution of the values of these properties over all categories within the type (e.g., the distribution of shapes, materials, summed over all object categories, $\boldsymbol{\beta}_{\mathbf{0}}$, and the distribution of shapes, materials, etc., summed over all substance categories, $\boldsymbol{\beta}_{\mathbf{s}}$ ). Finally, at a yet higher level, the model specifies the possible distributions of properties across types $(\lambda)$, which is assumed fixed in Kemp et al.'s simulations.

The model learns by sampling members of the individual categories and using their properties to update the lower level and midlevel statistical distributions. Figure 4 shows these samples as the $y$ 's at the bottom of the structure. In this way, the model can learn that categories within the object type are approximately uniform in shape but not material, whereas categories within the substance type are approximately uniform in material but not shape. The multiple levels allow members of categories within the object type to have the same shape (e.g., members of object category $o_{1}$ are square, whereas members of object category $o_{2}$ are circular) without forcing all members of the object type to have the same shape (e.g., members of both category $o_{1}$ and $o_{2}$ are square). Thus, if the model receives a new category $o_{3}$ with a triangularly shaped member, it will infer that other members of $o_{3}$ are triangular.

Like the connectionist model, the hierarchical Bayesian model can learn to predict that categories of solid items tend to have similar shapes and that categories of nonsolid items tend to have similar materials. But again, it is unclear that this is the appropriate distinction if the goal is to explain the concepts OBJECT and SUBSTANCE. Both theories are sufficiently general that they could learn to divide categories in a more appropriate way as atomic (individuated) versus nonatomic (nonindividuated). However, this may require attention to properties other than purely perceptual ones. The Bayesian model may have an advantage in this respect, since it can build in abstract distinctions like atomicity by means of its higher level structure. But although the model's layers can accommodate this abstract structure, it is not so clear that they can explain it. 


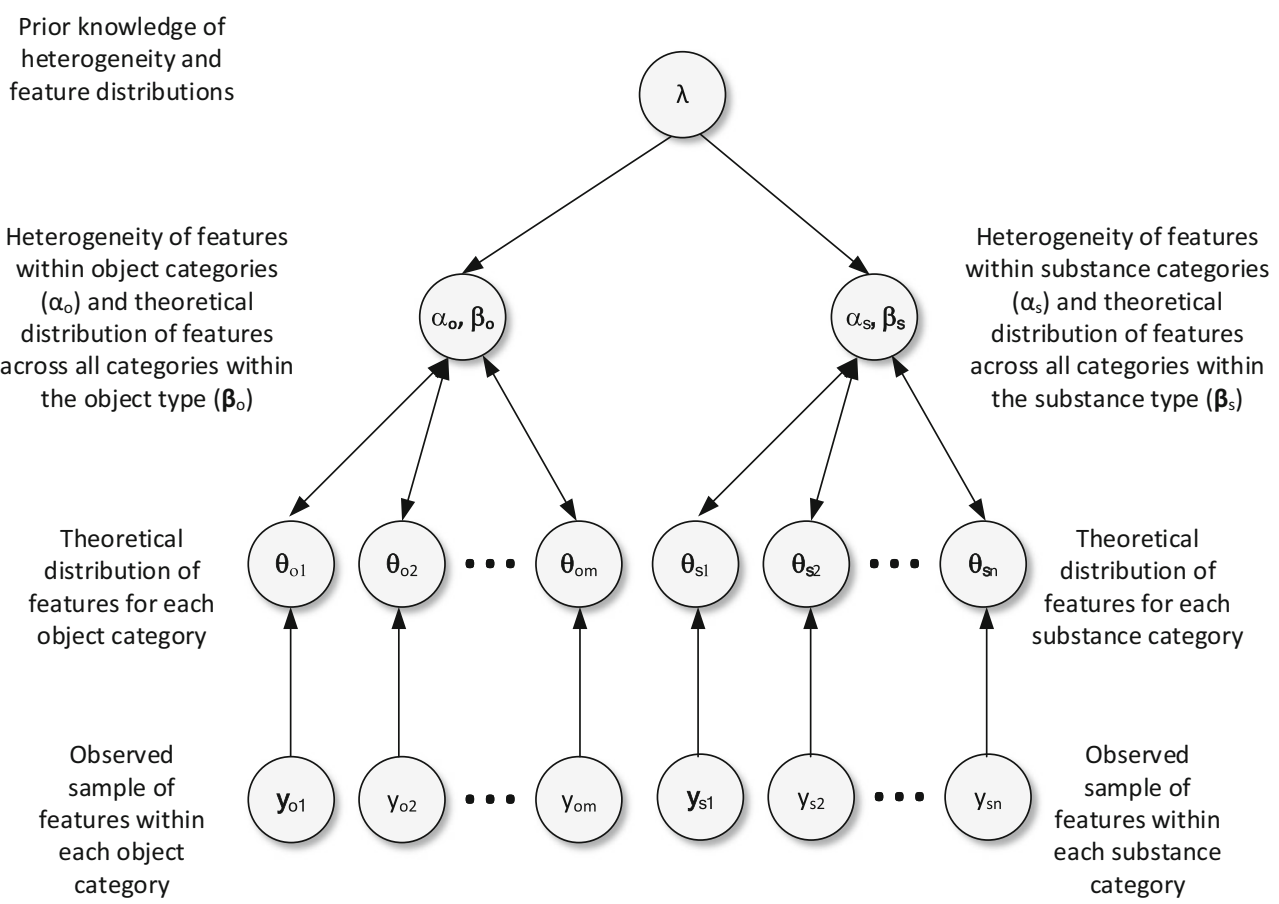

Fig. 4 A hierarchical Bayesian model for learning the association between individual nouns and their properties, based on Kemp, Perfors, and Tenenbaum (2007, Fig. 1). See text for description

Evidence from a comparison task A few additional crosslanguage studies have used the comparison task, discussed earlier (see the section on object mass nouns), in which participants decide "Which is more?" for objects and substances that vary in number and total volume. One option has a larger number of items, the other a larger total volume. The results of these studies present a striking contrast, illustrated in Fig. 5. Two of the studies looked at speakers of Japanese and Mandarin, both classifier languages whose nouns cannot directly combine with numerals (Barner, Inagaki, \& Li, 2009; Cheung, Li, \& Barner, 2012). The questions (in Japanese or Mandarin) asked "Which is more [noun]?" where the noun was one that English speakers would identify as referring to objects (e.g., balloons), substances (e.g., mustard), or either objects or substances (e.g., rocks or rock). No classifier appeared with the nouns. As Fig. 5 shows, adult participants answered in much the way that English speakers do (see Barner \& Snedeker, 2005): They chose by number for object-referring nouns, by volume for substance-referring nouns, with intermediate results for the flexible nouns. ${ }^{8}$

However, the results shift dramatically in a similar experiment with speakers of Yudja (Lima, 2018). As we mentioned earlier, Yudja has only count nouns, in the sense that any noun - including those for substances and aggregates - can combine directly with numerals (e.g., the Yudja equivalent of three waters). In the experiment, adult speakers of Yudja

\footnotetext{
${ }^{8}$ We have omitted from Fig. 5 studies that did not use all the $x$-axis categories (e.g., Deal, 2017).
}

were asked to decide "Who has more [noun]?", where the noun could refer to objects (e.g., spoons), substances (e.g., water), or aggregates. The latter were defined as "a naturally atomic individual whose instances can be of different types (e.g., abeata 'clothes' might refer to shirts, skirts, and wã'e 'ceramics' in Yudja might refer to different types of ceramic pans)" (Lima, 2018, p. 6). Figure 5 classifies these aggregate items as "intermediate," along with the flexible nouns from Barner et al. (2009) and Cheung et al. (2012). In accord with Yudja's count-noun dominance, adult speakers judged on $75 \%-85 \%$ of trials that the greater number of items was "more," rather than the items with the larger total volume. Referent type (object, substance, or aggregate) had no significant effect on these decisions. However, participants showed a less extreme pattern (55\%-65\% number responses) when answering the same questions in their second language, Brazilian Portuguese, which distinguishes count and mass nouns. Responses in Portuguese also showed more number responses for objects and aggregates than for substances. Thus, Yudja speakers can distinguish comparisons by number and comparisons by volume in the right context.

The Japanese-Mandarin experiments showed little effect of language on participants' decision to quantify by number or by volume, relative to the results from English speakers (compare the solid black line for English speakers in Fig. 5 with the large red dashes for speakers of Mandarin and Japanese). However, the results from Yudja (small green dashes) are quite different from English. Linguists sometimes describe classifier languages like Japanese and Mandarin as 


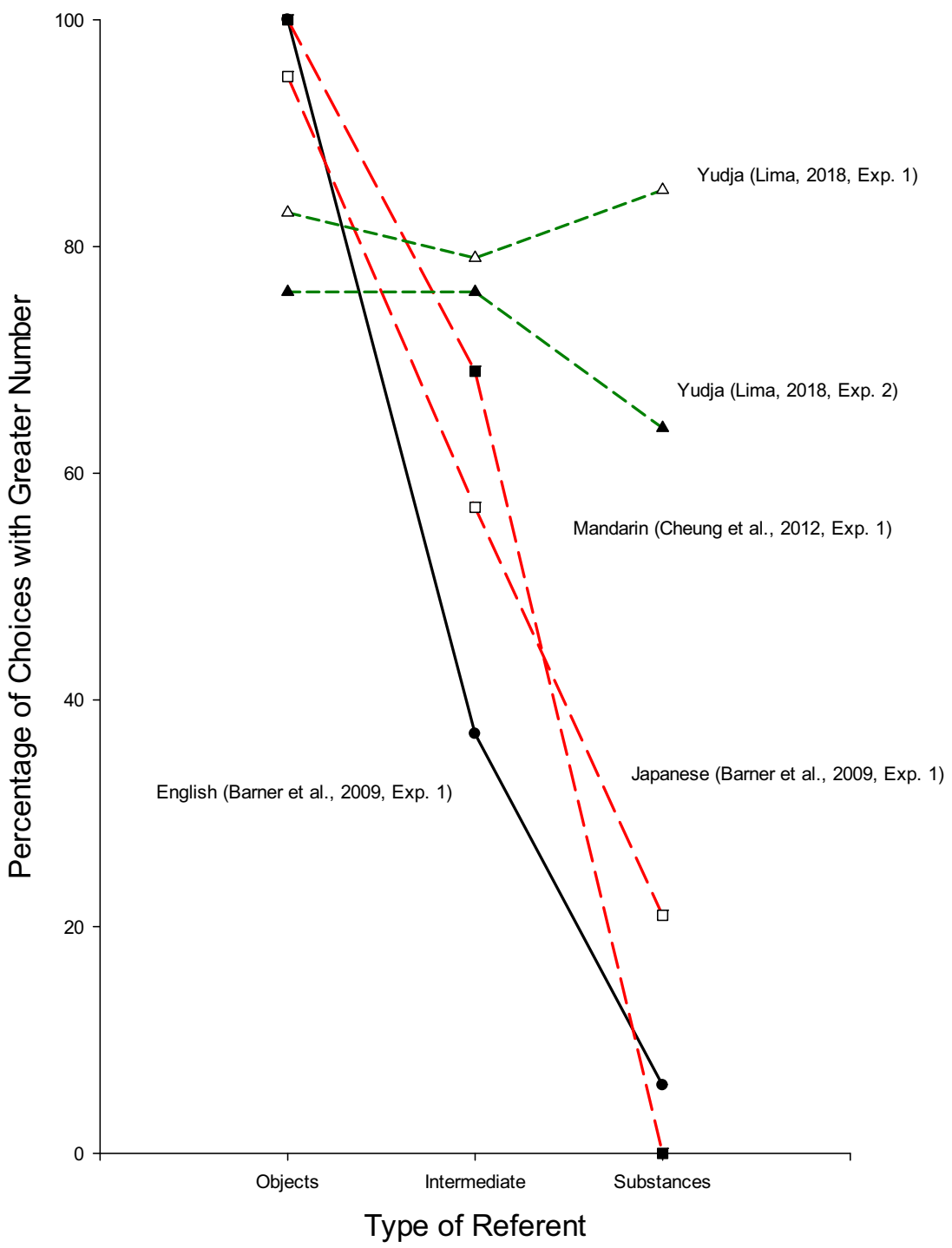

Fig. 5 Summary of results from cross-linguistic studies of how adults choose "Which is more?" where one option has a greater number (e.g., of eggs) and the other a greater volume. Intermediate items varied across studies: They were "aggregates" (e.g., clothes, ceramics) in Lima (2018),

containing only mass nouns and describe Yudja as containing only count nouns. If this is correct, why would all-mass languages be so similar to English while an all-count language be so different? This is especially puzzling, since most nouns in English are count. One possible explanation is that the comparison questions in these two sets of languages come with different conditions or presuppositions. "Which is more?" in Japanese and Mandarin may be neutral between number and measurement just as in English, but in Yudja may come with the extra requirement that it refers to the number of discrete elements. As Lima notes,

The results ... should not be taken as exemplifying that Yudja speakers perceive objects and substances and items denoted by flexible nouns (in English; e.g., rock, cake) in Barner et al. (2009) and Cheung et al. (2012). Lima (2018) pitted one against three items in Experiment 1 and two against six in Experiment 2. (Color figure online)

differently in different languages. Instead, it shows that the question Who has more $N ?$. . . is a different question when asked in Yudja or in Brazilian Portuguese, given the different grammatical properties of these languages with respect with the grammar of countability, and specifically the different semantics of nouns in both languages. (Lima, 2018, p. 14, emphasis in original)

Implications Differences like these highlight a predictably controversial issue: whether any of the cross-language results show that the grammatical differences affect the conceptual ones. Are speakers of classifier languages more prone to think of entities as substances than are speakers of number-marking languages or all-count-noun languages? Gleitman and 
Papafragou (2012) have proposed that the cross-language differences in Fig. 2 reflect English speakers' knowledge of the relative frequency of count and mass nouns. Because count nouns are more frequent in English than mass nouns, English speakers may correctly believe that a noun with undetermined count/mass status (e.g., snarb in Look at this snarb) is probably a count noun. And because count nouns refer to objects more often than to substances, the speakers may infer that the noun denotes an object. Gleitman and Papafragou's claim is not that speakers of number-marking languages refer to objects more frequently than speakers of classifier languages do (nor that speakers of number-marking languages find objects more salient than speakers of classifier languages do). Instead, the idea is that people know that count nouns are more frequent than mass nouns and use this bit of lexical statistics to figure out that an ambiguous noun is probably count. In terms of our dual framework, the relative frequency of count nouns inclines people to think that a novel unmarked noun is likely to be count and to refer to a member of the object domain. These inferences, though, are consistent with speakers of all languages recognizing the same division between domains. Suppose, for example, that an experimenter applies snarb to a simple entity, such as a chunk of wax. Speakers of both number-marking languages and classifier languages may identify the chunk with an entity in the object domain, and they may identify the wax with an entity in the substance domain. But the number-marking speakers may be more likely to think snarb refers to the object rather than its substance, since snarb is likely to be a count noun.

Support for this position comes from experiments that ask participants to decide explicitly whether a given entity is an object or a substance. If speaking a classifier language such as Japanese disposes people to classify entities as substances, then Japanese speakers should make more substance judgments than object judgments in this task. But contrary to this prediction, Japanese, Mandarin, and English speakers do not differ in their choice of whether pictured entities (solids, varying in perceptual complexity and functional relevance, and nonsolids) are objects or substances (Li et al., 2009). Similarly, Barner et al. (2009) found that Japanese and English speakers do not differ in their explicit object-orsubstance classifications for an array of nouns, varying from object-like (e.g., camera and pen or their Japanese translations) to substance-like (e.g., sugar and milk) and including potentially ambiguous items, such as paper. This evidence suggests that there is no effect of language on the conceptual boundary between objects and substances. Speakers of all languages recognize the same object/substance division. Instead, language affects the probability that speakers will identify a noun as referring to an entity on the object side or on the substance side of the boundary.

This conclusion is consistent with results on object tracking. In experiments of this kind (e.g., Pylyshyn \& Storm,
1988), participants view a set of items (e.g., 10 dots), some of which are initially tagged as targets. The tags then disappear, and the items move about randomly for a few seconds. When the items halt, participants must decide which of the items were the targets. Both children and adults perform more accurately in this procedure when the items maintain their shape as they move (as solid objects would) than if they deform as if streaming from one position to another (as some nonsolid substances would; vanMarle \& Scholl, 2003; vanMarle \& Wynn, 2011). If speakers of number-marking languages are more attuned to the distinction between objects and substances than are speakers of classifier languages, then the typical differences in performance with objects and substances might be larger for the former group. However, no such increase occurs for either child (5-6-year-old) or adult speakers of Swiss German relative to speakers of Japanese (Cacchione et al., 2014). Any effects of number-marking versus classifier languages apparently do not reach down far enough to influence visual tracking.

\section{Summary}

Preverbal infants have expectations about objects and substances. So any effects of language on substance and object concepts have to piggyback on this preexisting knowledge. The most likely place to observe such language effects is in classification of ambiguous entitiesfor example, pieces of clay that may or may not exhibit an object's characteristic shaping. Perhaps classifier languages, in which all nouns are arguably mass, incline their speakers to treat reference to such items as a reference to a substance. However, direct tests of this hypothesis have not confirmed it. People's experience with objects and substances may be similar across linguistic communities. So when a lumpy piece of clay comes into view, members of these communities may be about equally likely to think of the thing as an object. Effects of language on classification (see Fig. 2) may be indirect, perhaps through people's knowledge of the frequency of mass versus count expressions. Of course, more detailed testing in future studies may recover more robust language effects. For example, experiments might probe whether speakers of classifier languages are more likely to attribute substance properties to entities than are speakers of number-marking languages.

\section{General discussion}

There is something psychologically compelling about the difference between object and substance concepts. Infants from at least 5 months of age differentiate solid objects from nonsolid substances. And at least at first glance, the 
linguistic split between count and mass nouns seems to tap the same distinction, as in semantic theories by Krifka (1989), Link (1983), and others. The problem is that many clear counterexamples block a simple mapping between these distinctions, one in which count nouns refer to things in the object domain and mass nouns to stuff in the substance domain. These exceptions may make it reasonable to regard the distinctions as partially or wholly independent (e.g., Doetjes, 2017; Pelletier, 2012; Pelletier \& Schubert, 2003). How should we think about the relation between the two distinctions? What does the relation tell us about the concepts OBJECT and SUBSTANCE?

Although even infants recognize the difference between solid objects and nonsolid substances, children's learning of the count or mass status of a noun is more sensitive to syntactic than to semantic (i.e., referential) evidence. The two distinctions seem to develop in parallel. Of course, people eventually coordinate syntax and semantics. Children and adults know that count nouns usually refer to objects and that mass nouns usually refer to substances. So when discrepancies in this mapping arise, does this cause changes in the way people think about the OBJECT and SUBSTANCE concepts? For example, do they readjust what they think of as an object or a substance in light of the mismatching cases? To answer this question, we first looked at coercion in sentence comprehension, which might provide evidence for a shift in people's thinking from the object to the substance domain (or the reverse) when count nouns are used as mass (e.g., There's apple in the salad) or mass nouns are used as count (e.g., Bring us two beers). There is some evidence for such a switching effect, but, at this point, its cause is ambiguous and may be entirely a matter of syntactic adjustment.

A second source of evidence comes from object mass nouns (including mass superordinates), where the syntactic and semantic distinctions also clash. Object mass nouns, such as toast or pottery, are syntactically mass but seem to refer to discrete objects. Does the mass status of these nouns cause changes in our conception of their referents? Although some evidence points to distinct semantic properties of object mass nouns, it is unclear whether their mass-noun status alters our concepts of their referents.

A final source of evidence comes from cross-linguistic differences. Do people think about objects and substances differently if their language makes a count/mass distinction than if it does not? The main result here is that speakers of classifier languages tend to generalize nouns for ambiguous items (items on the borderline between objects and substances) according to their material rather than according to their shape (see Fig. 2). However, more recent results show that this effect is specific to contexts of naming or referring. People do not classify ambiguous items differently if they are directly asked whether the items are objects or substances. So again there seems to be a kind of independence between the distinctions. Number marking can alter whether people believe nouns refer to things (vs. stuff) but not their beliefs about the nature of the things (or stuff).

The overall message that emerges is that count/mass and OBJECT/SUBSTANCE are surprisingly independent in terms of the psychological processes that make use of them. They are not statistically independent: For example, most count nouns refer to solid items and to items with consistent shape, at least in children's early vocabulary (Colunga \& Smith, 2005; Samuelson \& Smith, 1999). But this correlation does not seem to have major implications for the way we think about objects and substances (and may be somewhat weaker, both within and across languages than one might expect; Kulkarni, Rothstein, \& Treves, 2013). It seems possible that our concepts of objects and substances start out as theories about the material world and may evolve as these theories evolve-as we learn more about the nature of their physical and chemical properties. The count/mass distinction may arise separately as a response to linguistic facts and may evolve as part of a formal system. People probably believe that there are statistical connections between these distinctions and can use the connection to inform their inferences. But there is little evidence that the linguistic facts transform the conceptual ones (recall our French/German and France/Germany analogy at the beginning of this article).

\section{Conclusions}

The research reviewed in this article suggests that the distinction between substances and objects is, for the most part, psychologically independent of the grammar of count and mass nouns. Children seem to acquire the grammatical distinction with little influence from their knowledge of typical objects and substances. And although the grammatical distinction seems to affect the way speakers of different languages generalize a novel noun's referent to other items, it seems to have little sway over the concepts OBJECT and SUBSTANCE themselves. This strongly suggests that popular procedures like the generalization task may not be tapping what is crucial about substances and objects. Future work may profit by using descriptions and scenarios of items that differ in abstract properties like atomicity, using techniques from the study of concepts and categories.

Acknowledgements We thank Erin Anderson, David Barner, Britta Biedermann, Yin-Juei Chang, Andrei Cimpian, Jacob Dink, Michelle Ellefson, John Glines, Samuel Johnson, Joshua Knobe, Sandy LaTourrette, Nick Leonard, Sandeep Prasada, Susan Rothstein, and Alexis Wellwood for their helpful comments on earlier versions of this article. 


\section{References}

Aguiar, A., \& Baillargeon, R. (1999). 2.5-month-old infants' reasoning about when objects should and should not be occluded. Cognitive Psychology, 39, 116-157.

Aikhenvald, A. Y. (2000). Classifiers: A typology of noun categorization devices. Oxford: Oxford University Press.

Allan, K. (1980). Nouns and countability. Language, 56, 541-567.

Anderson, E. M., Hespos, S. J., \& Rips, L. J. (2018). Five-month-old infants have expectations for the accumulation of nonsolid substances. Cognition, 175, 1-10. doi:https://doi.org/10.1016/j. cognition.2018.02.009

Aristotle. (1994). Metaphysics: Books Z and H. (D. Bostock, Ed. \& Trans.). Oxford: Oxford University Press.

$\mathrm{Au}, \mathrm{T}$. K. (1994). Developing an intuitive understanding of substance kinds. Cognitive Psychology, 27, 71-111. doi:https://doi.org/10. 1006/cogp.1994.1012

Baillargeon, R. (1995). A model of physical reasoning in infancy. In C. Rovee-Collier \& L. P. Lipsett (Eds.), Advances in infancy research (Vol. 9). 305-371. Norwood: Ablex.

Baillargeon, R. (2008). Innate ideas revisited: For a principle of persistence in infants' physical reasoning. Perspectives on Psychological Science, 3, 2-13. doi:https://doi.org/10.1111/j.1745-6916.2008. 00056.x

Bale, A. C., \& Barner, D. (2009). The interpretation of functional heads: Using comparatives to explore the mass/count distinction. Journal of Semantics, 26, 217-252. doi:https://doi.org/10.1093/jos/ffp003

Barner, D., Inagaki, S., \& Li, P. (2009). Language, thought, and real nouns. Cognition, 111, 329-344. doi:https://doi.org/10.1016/j. cognition.2009.02.008

Barner, D., \& Snedeker, J. (2005). Quantity judgments and individuation: Evidence that mass nouns count. Cognition, 97, 41-66. doi:https:// doi.org/10.1016/j.cognition.2004.06.009

Barner, D., Wagner, L., \& Snedeker, J. (2008). Events and the ontology of individuals: Verbs as a source of individuating mass and count nouns. Cognition, 106, 805-832. doi:https://doi.org/10.1016/j. cognition.2007.05.001

Bowerman, M. (1996). Learning how to structure space for language: A crosslinguistic perspective. In P. Bloom \& M. A. Peterson (Eds.), Language and space (pp. 385-436). Cambridge: MIT Press.

Cacchione, T., Indino, M., Fujita, K., Itakura, S., Matsuno, T., Schaub, S., \& Amici, F. (2014). Universal ontology: Attentive tracking of objects and substances across languages and over development. International Journal of Behavioral Development, 38, 481-486. doi:https://doi.org/10.1177/0165025414544233

Casasola, M., \& Cohen, L. (2002). Infant categorization of containment, support and tight-fit spatial relationships. Developmental Science, 5, 247-264. https://doi.org/10.1111/1467-7687.00226

Cheung, P., Li, P., \& Barner, D. (2012). What counts in Mandarin Chinese: A study of individuation and quantification. Proceedings of the 34th Annual Conference of the Cognitive Science Society, 34, 210-215.

Chien, Y. C., Lust, B., \& Chiang, C. P. (2003). Chinese children's comprehension of count-classifiers and mass-classifiers. Journal of East Asian Linguistics, 12, 91-120. doi:https://doi.org/10.1023/a: 1022401006521

Chierchia, G. (2010). Mass nouns, vagueness and semantic variation. Synthese, 174, 99-149. doi:https://doi.org/10.1007/s11229-0099686-6

Choi, S. \& Bowerman, M. (1991). Learning to express motion events in English and Korean: The influence of language-specific lexicalization patterns. Cognition, 41, 83-121.

Colunga, E., \& Smith, L. B. (2005). From the lexicon to expectations about kinds: A role for associative learning. Psychological Review, 112, 347-382. doi:https://doi.org/10.1037/0033-295x.112.2.347
Deal, A. R. (2017). Countability distinctions and semantic variation. Natural Language Semantics, 25, 125-171.

Dickinson, D. K. (1987). The development of a concept of material kind. Science Education, 71, 615- 628. doi:https://doi.org/10.1002/sc. 3730710412

Dickinson, D. K. (1988). Learning names for materials: Factors constraining and limiting hypotheses about word meaning. Cognitive Development, 3, 15-35. doi:https://doi.org/10.1016/ 0885-2014(88)90028-7

Doetjes, J. (2017). The count/mass distinction in grammar and cognition. Annual Review of Linguistics, 3, 199-217. doi:https://doi.org/10. 1146/annurev-linguistics-011516-034244

Fieder, N., Nickels, L., \& Biedermann, B. (2014). Representation and processing of mass and count nouns: A review. Frontiers in Psychology, 5, 1-18. doi:https://doi.org/10.3389/fpsyg.2014.00589

Fine, K. (1999). Things and their parts. Midwest Studies in Philosophy, $23,61-74$.

Frisson, S., \& Frazier, L. (2005). Carving up word meaning: Portioning and grinding. Journal of Memory and Language, 53, 277-291. doi: https://doi.org/10.1016/j.jml.2005.03.004

Gao, M. Y., \& Malt, B. C. (2009). Mental representation and cognitive consequences of Chinese individual classifiers. Language and Cognitive Processes, 24, 1124-1179. doi:https://doi.org/10.1080/ 01690960802018323

Gathercole, V. C. (1985). 'He has too much hard questions': The acquisition of the linguistic mass-count distinction in much and many. Journal of Child Language, 12, 395-415. doi:https://doi.org/10. 1017/S0305000900006504

Gathercole, V. C. M., \& Min, H. (1997). Word meaning biases or language-specific effects? Evidence from English, Spanish and Korean. First Language, 17, 31-56. doi:https://doi.org/10.1177/ 014272379701705102

Gillon, B., Kehayia, E., \& Taler, V. (1999). The mass/count distinction: Evidence from on-line psycholinguistic performance. Brain and Language, 68, 205-211.

Gillon, B. S. (2012). Mass terms. Philosophy Compass, 7, 712-730. doi: https://doi.org/10.1111/j.1747-9991.2012.00514.x

Gleitman, L., \& Papafragou, A. (2012). New perspectives on language and thought. In K. J. Holyoak \& R. G. Morrison (Eds.), Oxford handbook of thinking and reasoning (pp. 543-568). New York: Oxford University Press.

Gordon, P. (1985). Evaluating the semantic categories hypothesis: The case of the count/mass distinction. Cognition, 20, 209-242. doi: https://doi.org/10.1016/0010-0277(85)90009-5

Grimm, S. (2018). Grammatical number and the scale of individuation. Language, 94, 527-574.

Grimm, S., \& Levin, B. (2012). Who has more furniture? An exploration of the bases for comparison. Paper presented at the Mass/Count in Linguistics, Philosophy and Cognitive Science Conference, École Normale Supérieure, Paris. Retrieved from http://www.stanford.edu/ $\sim$ bclevin/paris 12 mcslides.pdf

Hall, D. G. (1996). Naming solids and nonsolids: Children's default construals. Cognitive Development, 11, 229-264. doi:https://doi. org/10.1016/s0885-2014(96)90004-0

Hespos, S. J., \& Baillargeon, R. (2001). Infants' knowledge about occlusion and containment: A surprising discrepancy. Psychological Science, 12, 141-147.

Hespos, S. J., Ferry, A. L., Anderson, E. M., Hollenbeck, E. N., \& Rips, L. J. (2016). Five-month-old infants have general knowledge of how nonsolid substances behave and interact. Psychological Science, 27, 244-256.

Hespos, S. J., Ferry, A. L., \& Rips, L. J. (2009). Five-month-old infants have different expectations for solids and liquids. Psychological Science, 20, 603-611. doi:https://doi.org/10.1111/j.1467-9280. 2009.02331.x 
Hespos, S. J., \& Spelke, E. S. (2004). Conceptual precursors to language. Nature, 430, 453-456. doi:https://doi.org/10.1038/nature02634

Imai, M., \& Gentner, D. (1997). A cross-linguistic study of early word meaning: Universal ontology and linguistic influence. Cognition, 62, 169-200. doi:https://doi.org/10.1016/s0010-0277(96)00784-6

Imai, M., \& Mazuka, R. (2007). Language-relative construal of individuation constrained by universal ontology: Revisiting language universals and linguistic relativity. Cognitive Science, 31, 385-413. doi: https://doi.org/10.1080/15326900701326436

Johnston, M. (2006). Hylomorphism. Journal of Philosophy, 103, 652698.

Keil, F. C. (1979). Semantic and conceptual development: An ontological perspective. Cambridge: Harvard University Press.

Kemp, C., Perfors, A., \& Tenenbaum, J. B. (2007). Learning overhypotheses with hierarchical Bayesian models. Developmental Science, 10, 307-321. doi:https://doi.org/10.1111/j.1467-7687. 2007.00585.x

Koslicki, K. (2008). The structure of objects. Oxford: Oxford University Press.

Krifka, M. (1989). Nominal reference, temporal constitution and quantification in event semantics. In R. Bartsch, J. V. Benthem \& P. V. E. Boas (Eds.), Semantics and contextual expression (pp. 75-115). Dordrecht: Foris Publications.

Kulkarni, R., Rothstein, S., \& Treves, A. (2013). A statistical investigation into the cross-linguistic distribution of mass and count nouns: Morphosyntactic and semantic perspectives. Biolinguistics, 7, 132168.

Li, P., Dunham, Y., \& Carey, S. (2009). Of substance: The nature of language effects on entity construal. Cognitive Psychology, 58, 487-524. doi:https://doi.org/10.1016/j.cogpsych.2008.12.001

Lima, S. (2018). Quantity judgment studies in Yudja (Tupi): Acquisition and interpretation of nouns. Glossa, 3, 1-16. doi:https://doi.org/10. 5334/gjgl.359

Link, G. (1983). The logical analysis of plurals and mass terms: A latticetheoretical approach. In R. Bauerle, C. Schwarze, \& A. von Stechow (Eds.), Meaning, use, and interpretation of language (pp. 302-323). Berlin: de Gruyter

Lucy, J. A., \& Gaskins, S. (2003). Interaction of language type and referent type in the development of nonverbal classification preferences. In D. Gentner \& S. Goldin-Meadow (Eds.), Language in mind: Advances in the study of language and thought (pp. 465492). Cambridge: MIT Press.

Markman, E. M. (1985). Why superordinate category terms can be mass nouns. Cognition, 19, 31-53. doi:https://doi.org/10.1016/00100277(85)90030-7

McDonough, L., Choi, S., \& Mandler, J. M. (2003). Understanding spatial relations: Flexible infants, lexical adults. Cognitive Psychology, 46, 229-259.

McPherson, L. M. P. (1991). A little goes a long way: Evidence for a perceptual basis of learning for the noun categories count and mass. Journal of Child Language, 18, 315-338. doi:https://doi.org/10. 1017/s0305000900011089

Middleton, E. L., Wisniewski, E. J., Trindel, K. A., \& Imai, M. (2004). Separating the chaff from the oats: Evidence for a conceptual distinction between count noun and mass noun aggregates. Journal of Memory and Language, 50, 371-394. doi:https://doi.org/10.1016/j. jml.2004.02.005

Nickels, L., Biedermann, B., Fieder, N., \& Schiller, N. O. (2015). The lexical-syntactic representation of number. Language, Cognition and Neuroscience, 30, 287-304. doi:https://doi.org/10.1080/ 23273798.2013 .879191

Pelletier, F. J. (2012). Mass terms. In G. Russell \& D. G. Fara (Eds.), Routledge companion to the philosophy of language (pp. 424-437). London: Routledge.
Pelletier, F. J., \& Schubert, L. K. (2003). Mass expressions. In D. M. Gabbay \& F. Guenthner (Eds.), Handbook of philosophical logic (2nd ed., Vol. 10, pp. 249-335). Dordrecht: Kluwer.

Prasada, S., Ferenz, K., \& Haskell, T. (2002). Conceiving of entities as objects and as stuff. Cognition, 83, 141-165. doi:https://doi.org/10. 1016/s0010-0277(01)00173-1

Pylyshyn, Z., \& Storm, R. W. (1988). Tracking multiple independent targets: Evidence for a parallel tracking mechanism. Spatial Vision, 3, 179-197.

Rips, L. J., \& Hespos, S. J. (2015). Divisions of the physical world: Concepts of objects and substances. Psychological Bulletin, 141, 786-811.

Rosen, A. B., \& Rozin, P. (1993). Now you see it, now you don't: The preschool child's conception of invisible particles in the context of dissolving. Developmental Psychology, 29, 300-311. doi:https://doi. org/10.1037/0012-1649.29.2.300

Rothstein, S. (2010). Counting and the mass/count distinction. Journal of Semantics, 27, 343-397.

Rothstein, S. (2017). Semantics for counting and measuring. Cambridge: Cambridge University Press.

Samuelson, L. K., \& Smith, L. B. (1999). Early noun vocabularies: Do ontology, category structure and syntax correspond? Cognition, 73, 1-33. doi:https://doi.org/10.1016/s0010-0277(99)00034-7

Sattig, T. (2010). Compatibilism about coincidence. Philosophical Review, 119, 273-313. doi:https://doi.org/10.1215/003181082010-001

Sera, M. D., \& Goodrich, W. (2010). Who thinks that a piece of furniture refers to a broken couch? Count-mass constructions and individuation in English and Spanish. Cognitive Linguistics, 21, 179-442. doi:https://doi.org/10.1515/cogl.2010.015

Shapiro, L. P., Zurif, E., Carey, S., \& Grossman, M. (1989). Comprehension of lexical subcategory distinctions by aphasic patients. Journal of Speech and Hearing Research, 32, 481-488. doi: https://doi.org/10.1044/jshr.3203.481

Snape, N. (2008). Resetting the nominal mapping parameter in L2 English: Definite article use and the count-mass distinction. Bilingualism, 11, 63-79. doi:https://doi.org/10.1017/ S1366728907003215

Soja, N. N. (1992). Inferences about the meanings of nouns: The relationship between perception and syntax. Cognitive Development, 7 , 29-45. doi:https://doi.org/10.1016/0885-2014(92)90003-a

Soja, N. N., Carey, S., \& Spelke, E. S. (1991). Ontological categories guide young children's inductions of word meaning: Object terms and substance terms. Cognition, 38, 179-211. doi:https://doi.org/10. 1016/0010-0277(91)90051-5

Spelke, E. S. (1990). Principles of object perception. Cognitive Science, 14, 29-56. doi:https://doi.org/10.1207/s15516709cog1401_3

Spelke, E. S., Breinlinger, K., Macomber, J., \& Jacobson, K. (1992). Origins of knowledge. Psychological Review, 99, 605-632. doi: https://doi.org/10.1037/0033-295x.99.4.605

Strickland, B. (2017). Language reflects 'core' cognition: A new theory about the origin of cross-linguistic regularities. Cognitive Science, 41, 70-101. doi:https://doi.org/10.1111/cogs. 12332

Subrahmanyam, K., Landau, B., \& Gelman, R. (1999). Shape, material, and syntax: Interacting forces in children's learning in novel words for objects and substances. Language and Cognitive Processes, 14, 249-281.

Sutton, P., \& Filip, H. (2016a). Counting in context: Count/mass variation and restrictions on coercion in collective artifact nouns. Proceedings from Semantics and Linguistic Theory, 26, 350-370.

Sutton, P. R., \& Filip, H. (2016b). Mass/count variation: A mereological, two-dimensional semantics. Baltic International Yearbook of Cognition, Logic and Communication, 11, 1-45. doi:https://doi. org/10.4148/1944-3676.1110 
Takatori, Y., \& Schwanenflugel, P. J. (1992). Superordinate category terms and mass-count noun status. Journal of Linguistic Anthropology, 2, 199-209.

Taler, V., \& Jarema, G. (2007). Lexical access in younger and older adults: The case of the mass/count distinction. Canadian Journal of Experimental Psychology, 61, 21-34.

vanMarle, K., \& Scholl, B. J. (2003). Attentive tracking of objects versus substances. Psychological Science, 14, 498-504. doi:https://doi.org/ $10.1111 / 1467-9280.03451$

vanMarle, K., \& Wynn, K. (2011). Tracking and quantifying objects and non-cohesive substances. Developmental Science, 14, 502-515. doi: https://doi.org/10.1111/j.1467-7687.2010.00998.x

Wellwood, A., Hacquard, V., \& Pancheva, R. (2012). Measuring and comparing individuals and events. Journal of Semantics, 29, 207228.

Wierzbicka, A. (1988). The semantics of grammar, Amsterdam: John Benjamins.
Wisniewski, E. J., Imai, M., \& Casey, L. (1996). On the equivalence of superordinate concepts. Cognition, 60, 269-298. doi:https://doi.org/ 10.1016/0010-0277(96)00707-x

Wisniewski, E. J., Lamb, C. A., \& Middleton, E. L. (2003). On the conceptual basis for the count and mass noun distinction. Language and Cognitive Processes, 18, 583-624. doi:https://doi. org/10.1080/01690960344000044

\section{Open practices statement}

This article is a review of previous research, and no new data are reported here.

Publisher's note Springer Nature remains neutral with regard to jurisdictional claims in published maps and institutional affiliations. 